\title{
APLICAÇÃO DA FILOSOFIA KAIZEN EM UMA CÉLULA DE MONTAGEM DE UMA EMPRESA DE SEGURANÇA ELETRÔNICA
}

\author{
José Adilson Laurindo' \\ Ludimila Aparecida de Oliveira Lima² \\ Aline Cristina Maciel $^{3}$
}

Resumo: Este trabalho apresenta a aplicação da filosofia Kaizen em uma linha de produção em uma empresa do ramo de segurança eletrônica localizada no distrito industrial de Santa Rita do Sapucaí- MG. O objetivo dessa filosofia é a melhoria contínua nos processos e produtos da empresa. Sendo assim foram realizadas reuniões e tarefas com a equipe, nas quais se buscam obter resultados e melhorias durante o período de uma semana. Foram utilizadas ferramentas da produção enxuta para analisar os processos. Da mesma forma foram identificados os problemas e suas respectivas causas raízes e, implementadas ações de melhorias. Assim, são apresentados dois momentos distintos, o anterior à aplicação da técnica de eventos Kaizen e pós-aplicação da mesma. Como resultado foi evidenciado aumento de produtividade da célula em cerca de 8,33\%, houve a eliminação de um posto de trabalho, com a liberação de um operador para outra linha produtiva, na qual o mesmo se fazia necessário. Houve ainda a redução do custo de fabricação, do produto estudado, em cerca de 20,60\%, bem como a implantação de 18 melhorias na célula em questão, ambas superando as metas do início do evento.

Palavras-chave: Melhoria continua; Produção enxuta; Kaizen.

\footnotetext{
1 Engenharia de Produção/Centro Universitário de Itajubá, Brasil. E-mail: j.adilsonlaurindo@yahoo.com.br.

2 Engenharia de Produção/Centro Universitário de Itajubá, Brasil. E-mail: ludoliveiralima11@hotmail.com.

${ }^{3}$ Engenharia de Produção/Centro Universitário de Itajubá, Brasil. E-mail: alinecrismaciel@gmail.com.
} 